\title{
A Geospatial Analysis of Shark Attack Rates for the Coast of California: 1994-2010
}

\author{
Raid Amin \\ University of Westflorida, United States \\ E-mail:ramin@uwf.edu \\ Erich K Ritter (Corresponding author) \\ Shark Research Institute, United States \\ E-mail: erichritter@att.net \\ Laura Cossette \\ University of Westflorida, United States \\ E-mail: lauralc6904@gmail.com
}

Received: October 22, 2012 Accepted: November 8, 2012 Published: December 31, 2012

doi:10.5296/jee.v3i1.2700

URL: http://dx.doi.org/10.5296/jee.v3i1.2700

\begin{abstract}
The subject of this investigation was spatial and spatio-temporal shark attack clusters occurring along California's coast between 1994 and 2010. Two hypotheses were postulated: (a) Shark attacks are proportionate to human beach activities. (b) No pronounced space-time relationship between human beach activity and shark attacks exists along this coast over time. The hypotheses were tested by using SaTScan ${ }^{\mathrm{TM}}$ version 9.1.1, a spatial scan statistic program. The results show that well-defined high- and low-risk areas have prevailed along the coast over the years. Because most attacks in California waters are attributed to white sharks, this animal was used as a model species to discuss the results.
\end{abstract}

Keywords: California, Geospatial, Cluster, SaTScan, Shark attack, Risk zones 


\section{Introduction}

Factors triggering shark attacks remain of prime interest in popular and scientific shark literature, with focuses on determining the effects on tourism and beaches that need monitoring (Amin, Ritter, \& Kennedy, 2012), evaluating scientific data to improve understanding of a person's effect on the approach behavior of sharks (e.g., Ritter \& Amin, 2012), and investigating what attracts sharks in the first place (e.g., Ritter \& Levine, 2004, 2005). Although the motivation to improve understanding of shark attacks varies, when and where incidents normally occur is clear: in environmental circumstances (a) most favorable for people to enjoy their water activities and (b) where sharks generally pursue their natural behaviors of hunting, mating, or giving birth. Because of this simple overlap, the shark-human conflict is naturally spread along coastal stretches all over the world. Some areas are environmentally more suitable for sharks than others; in the United States, the California and Florida coasts are the most incident prone, accounting for more than two thirds of all attacks in the continental United States. Historically, research has been predominantly focused on the "hot spots" along these coasts and less or not at all on the attack-free or less attack-prone areas nearby. Such focus reflects a reasonable approach as far as the number of attacks is concerned, but it falls short of giving a broader view about the true value of an increased or a decreased number of attacks within a region. Amin et al. (2012) showed, for Florida's coast, that a clearer understanding of shark attacks can be achieved by shifting focus from the number of attacks to the rate of attacks by including the beach-going population, giving the actual number of attacks more meaning. This approach offers the opportunity to study areas with fewer or no interactions as well as the previously determined hot spots. This approach can be of great importance should one focus, for example, on comparing environmental differences between contrasting areas, the lack or presence of human-triggered factors, and other variables.

This project was focused on gaining a better understanding of shark attacks along California's coast between 1994 and 2010, using attack rates and the same cluster analysis approach as previously applied to Florida (Amin et al., 2012). The two hypotheses - that shark attacks are proportionate to human beach activities and that no pronounced space-time relationship between human activities and shark attacks exists along this coast over time-were tested with a modern cluster analysis algorithm (SaTScan ${ }^{\mathrm{TM}}$ 9.1.1). One of California's main differences from Florida is that a large percentage of these attacks can be attributed to white sharks, Carcharodon carcharias (needs to be in italic), making this animal the best species to use in showing how attack rates and their potential high- and low-risk areas can be interpreted.

\section{Materials and Methods}

\subsection{Data Sources}

A shark attack rate was defined as the ratio between the yearly number of shark attacks for a given region and the yearly estimated beach attendance for the same region. The best possible number of people frequenting a beach would be the annual number of people who actually enter the water at a given location, but such data do not exist. The best approximation is 
offered by the United States Lifesaving Association (USLA). The USLA, a non-profit professional association of beach lifeguards, keeps data for annual attendance for the beaches at which its lifeguards are present. Even though these data reflect strictly beach attendance, they served as a sufficient proxy given the assumption that the same proportion of people frequenting a beach will also enter the water. However, this proxy contained two deficiencies that required correction: Some data of people attending a specific beach were not distinct enough with respect to its location or were even absent for some locations. Furthermore, large counties, such as Humboldt, Mendocino, or San Diego, needed to be broken into smaller units to make the analysis more spatially specific. Additionally, because beach populations within the smaller units were not likely to be the same for every unit, the population was weighted with respect to the coastal populations. In cases where population data were missing, adjacent beaches with known populations were used to approximate the population.

The shark attack data were obtained from the Shark Research Institute's "Global Shark Attack File" (2012). Exclusion of an incident and definition of a shark attack followed Amin et al. (2012).

\subsection{Data Analysis}

The software SaTScan ${ }^{\mathrm{TM}}$ version 9.1.1 uses a scan statistic to identify clusters and tests each cluster for significance. For California, this cluster analysis program was applied to evaluate the shark attack data for the entire coast between the years 1994 and 2010. The number and rate of shark attacks in each coastal region were used in a two-dimensional way for a spatial analysis and, with the time factor, in a three-dimensional way for a space-time analysis. This method tested the two null hypotheses: (a) Shark attacks are proportionate to human beach activities, and (b) no pronounced space-time relationship between human beach activity and shark attacks exists along this coast over time. For SaTScan ${ }^{\mathrm{TM}}$ to be used, each region along California's coast had to be defined through a centroid, which was calculated through ArcGIS. The spatial scan statistic then identified clusters by imposing variable-sized scanning windows that move over a map, including different sets of neighboring coastal regions in the window. If the window included the centroid of a specific coastal region, then this region was included in the window. The center of the window was positioned only at the county centroids, and the radius varied from zero (only one county included) to $50 \%$ of the population at risk. The method then adjusted for the multiple testing inherent in the thousands of overlapping circles evaluated as potential clusters.

The space-time scan statistic, on the other hand, was defined by a cylindrical window with a circular geographic base and a height corresponding to time. The base was defined as for the purely spatial scan statistic, and the height reflected the time span of potential clusters. The cylindrical window was then moved in space and time so that, for each possible geographic location and size, it visited each possible time span. In effect, an infinite number of overlapping cylinders of different sizes and shapes could be obtained, covering the entire study region, with each cylinder reflecting a possible cluster. Additional information for this method can be found in Amin et al. (2012). 


\section{Ml Macrothink}

Through a Monte Carlo simulation, we then generated 999 random replications of the data set to obtain the statistical stability for the identified clusters in the SaTScan ${ }^{\mathrm{TM}}$ program. SaTScan ${ }^{\mathrm{TM}}$ identified and listed shark attack clusters in order of significance. SaTScan ${ }^{\mathrm{TM}}$ first identified a "most likely cluster," followed by "secondary clusters," such that the $p$ value for each cluster is compared to a pre-set significance level of 0.05 . The latest version of SaTScan $^{\mathrm{TM}}$ v9.1.1 uses a Gumbel distribution approximation for the $\mathrm{p}$ values, making it possible to obtain more precise $\mathrm{p}$ values for a given number of Monte Carlo replicates (Abrams, Kleinman, \& Kulldorff, 2010).

\section{Results}

Spatial analysis revealed one high-risk area along the California coast (regions 1-9) and two significant low-risk clusters for the regions 17-19 and 20-22 (Figure 1). Table 1 shows the number of true and expected attacks, the percentage of risk increase and decrease (needs to be erased), the relative risks and attack rates, and the probabilities that the respective clusters were due to random causes. The purely spatial analysis did (to be replaced with 'can') not indicate when a shark attack cluster appeared, so a space-time analysis was performed for the period 1994-2010. Assessing these clusters using the Poisson model in SaTScan ${ }^{\mathrm{TM}}$ showed few differences (Figure 2). Regions 1-10 again appeared as the most likely temporal cluster, with elevated risk for the period 2003-2010, whereas the second strongest cluster occurred around regions 13-16 in 1995 (Table 2). Similarly, regions 18-19 and 20-22 were identified in 2001-2008 and 1996-2001 as primary and secondary low-risk areas, respectively.

Table 1. Spatial data for the high- and low-risk cluster areas in California between 1994 and 2010 for all attacks

$\mathrm{R}_{\text {red }}$, relative risk; $\mathrm{N}_{\text {true }}$, true number of attacks; $\mathrm{RR}$, relative risk; $\mathrm{N}_{\text {exp }}$, expected number of attacks; $\mathrm{R}_{\mathrm{att}}$, attack rate; and $\mathrm{p}$, $\mathrm{p}$-value of log likelihood ratio test.

\begin{tabular}{lllllll}
\hline Area & $\mathrm{R}_{\text {red }}$ & $\mathrm{N}_{\text {true }}$ & $\mathrm{RR}$ & $\mathrm{N}_{\exp }$ & $\mathrm{R}_{\text {att }}$ & $\mathrm{p}$ \\
\hline$[1-9]$ & Primary high & 25 & 150.01 & 0.31 & 0.00003510 & 0.0000 \\
{$[14-17]$} & Secondary high & 3 & 3.49 & 0.90 & 0.00000145 & 0.5170 \\
{$[18-19]$} & Primary low & 7 & 0.19 & 24.7 & 0.00000001 & 0.0000 \\
{$[11-13]$} & Secondary low & 13 & 0.37 & 24.96 & 0.00000023 & 0.0100 \\
\hline
\end{tabular}




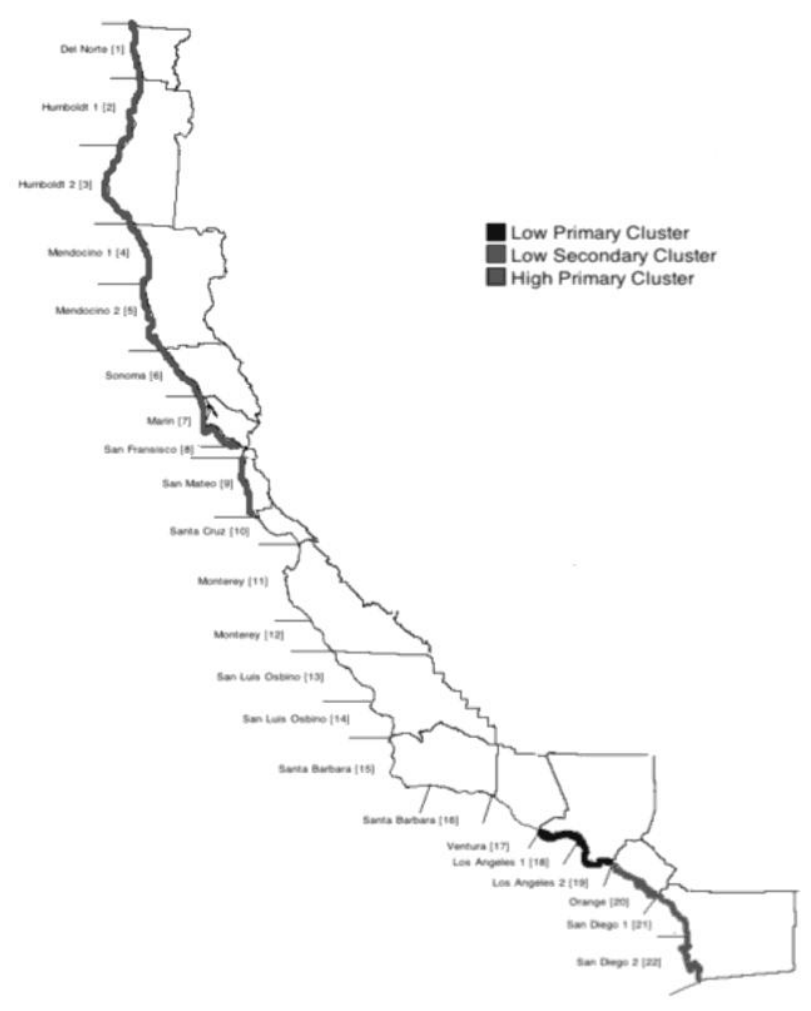

Figure 1. Spatial analysis of low and high primary and secondary attack clusters between 1994 and 2010. Numbers in brackets represent attacks over time period.

Table 2. Time spatial data for the high- and low-risk cluster areas in California between 1994 and 2010 for all attacks

$\mathrm{R}_{\text {red }}$, relative risk; $\mathrm{N}_{\text {true }}$, true number of attacks; $\mathrm{RR}$, relative Risk; $\mathrm{N}_{\text {exp }}$, expected number of attacks; Period, years during which cluster remained; and p, p-value of log likelihood ratio test.

\begin{tabular}{lllllll}
\hline Area & $\mathrm{R}_{\text {red }}$ & $\mathrm{N}_{\text {true }}$ & $\mathrm{RR}$ & $\mathrm{N}_{\exp }$ & Period & $\mathrm{p}$ \\
\hline$[1-9]$ & Primary high & 18 & 158.39 & 0.17 & $2003-2010$ & 0.0000 \\
{$[13-16]$} & Secondary high & 3 & 41.61 & 0.076 & $2007-2007$ & 0.0270 \\
{$[18-19]$} & Primary low & 1 & 0.072 & 11.22 & $2001-2008$ & 0.0017 \\
{$[20-22]$} & Secondary low & 0 & 0 & 8.23 & $1996-2001$ & 0.0018 \\
\hline
\end{tabular}




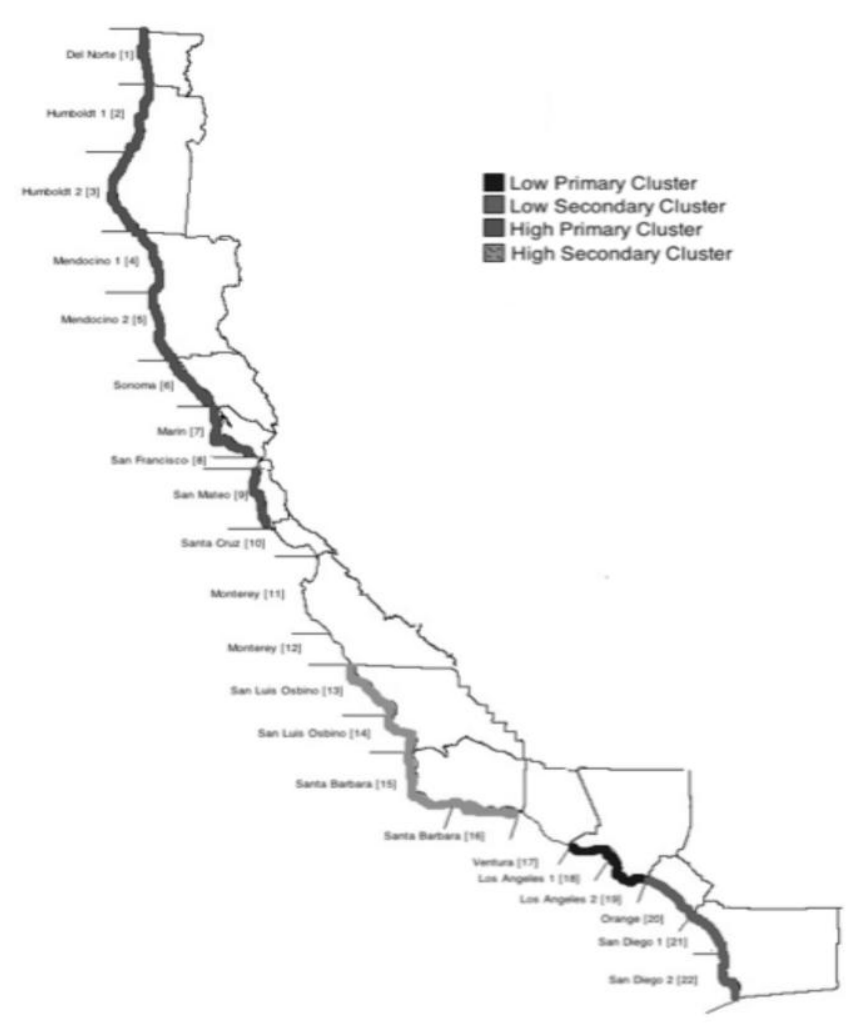

Figure 2. Space-time analysis of low and high primary and secondary attack clusters between 1994 and 2010. Numbers in brackets represent attacks over time period.

\section{Discussion}

In October 2012, within one week, California experienced two white shark attacks on surfers, one off Lompoc and the other off Eureka; one of the two attacked persons was killed. These two geographic areas rarely see any incidents according to traditional shark attack numbers. However, if shark attack rates based on Amin et al. (2012) are applied, both incidents occurred within high-risk shark-attack coastal zones.

This project used attack rates and was focused on quantitative analysis of California's shark attacks from the spatial and spatio-temporal perspectives, using cluster analysis. The results indicated several areas along California's coast with either a significant increase or a significant decrease in attack rates. Significant space-time clusters signified that observed shark attack rates are not purely spatial or purely temporal, indicating specific time spans during which shark attack rates were higher or lower than expected.

This discussion reflects the first application of attack rate for California waters, pinpointing high- and low-risk areas. The following explanations demonstrate the potential this new tool offers and serve as a base for additional research along this coast. The space-time clusters 
along California's coast are highly distinguished and remain largely the same for several years at a time. Similar outcomes have already been identified for the east coast of Florida, one of the world's premier locations for shark attacks (Amin et al., 2012). One of the main differences in attack analysis between the two states, however, is that, in Florida, identification of the shark species involved is largely lacking. For California, the species has been identified in about $75 \%$ of all occurrences, with more than $90 \%$ being attributed to the white shark. It is the most dominant species involved in the high- and low-risk clusters along the coast line (needs to be one word "coastline"). Although other species, to a lesser extent, are involved in incidents, the white shark's behavioral pattern most prominently affects the risk zones. This first study is somewhat limited because other data beyond the number of bites and the beach-going population do not exist, making this discussion still somewhat speculative.

\subsection{High-risk zones (HRZs)}

Over 8 years, spanning 2003-2010, the coastal area between San Mateo and Del Norte at the northern state border had a well-defined high-risk zone. Some spots within this HRZ had previously been identified as being of higher risk-though merely based on attack numbers - by Collier (1992), who identified Bodega Bay-Tomales Point, Pigeon Point, Point Conception, and Franklin Point as high risk. Kelly and Klimley (2003) added Point Reyes as an additional hot spot. Using the white shark as the main species involved, the most prominent denominator of all these locations and the entire high-risk cluster zone would be pinniped colonies, the preferred food source for larger white sharks (e.g., McCosker \& Lea, 2006). That these sites are reliable sources for pinnipeds (Kelly \& Klimley, 2003) would keep or draw white sharks closer to shore and, inevitably, in contact with humans. This situation would further be enhanced by several islands with large pinniped colonies, like the Farallons, Ana Nuevo, and Miguel Island, situated relatively close to the shore-based high-risk cluster areas.

\subsection{Low-risk zones (LRZ)}

The primary HRZs stand in stark contrast to the LRZs south of Santa Barbara and Point Conception, with shark attack numbers remaining largely the same between 2001 and 2008. The LRZs could easily be explained by referring again to white sharks. Concerning their migration patterns, this area south of Point Conception is seasonally frequented by mature females to give birth, so it is considered a prominent nursery area for this species. These females migrate back to the north after parturition, possibly reflecting one of the reasons that the area is considered a LRZ. The extent to which non-breeding female and mature male white sharks patrol these southern waters is not known. Despite this area being a LRZ, when pregnant females reside in these waters, an increase in attack numbers occurs. This increase, however, does not significantly affect attack rates because warmer water occurs in late summer; hence, there are proportionately more beach goers.

Although, for most incidents in California waters, general size estimations of the sharks involved have been given, the sharks' factual sizes need to be verified. Such determination of animal size based on wound dimensions or damage to surfboards and kayaks is currently 
being conducted (unpubl. data of ER). That small-sized white sharks have been involved in some of the incidents has already been verified (Shark Research Institute, 2012). These smaller sharks are probably drawn closer to shore because of their preference for demersal fishes, which they hunt close to the seafloor but relatively inshore (Dewar, Domeier, \& Nasby-Lucas, 2004). However, there is also the possibility that cannibalistic pressure from larger white sharks pushes young-of-the-year and other smaller animals closer to shore, but this possibility needs further investigation.

\subsection{Reproductive Cycles and Risk Zones}

It is known that female white sharks have at least a 2-year-possibly even a 3-year-reproductive cycle (Mollet, Cliff, Pratt, \& Stevens, 2000), and a considerable number of these females might remain within or close to the primary HRZ and, consequently, would not migrate south into the parturition area, the LRZ. The reproductive cycle of female white sharks influences their presence not only in southern California waters but also in a second area far out in the Pacific. In addition, mature white sharks of both genders migrate at the end of winter and beginning of spring for mating and foraging (e.g., Domeier \& Nasby-Lucas, 2008; Jorgensen et al., 2009). Males return to the primary HRZ earlier than females do, but both genders are present later in summer, although chances are that some females return only in alternate years (Nasby-Lucas, Dewar, Lam, Goldman, \& Domeier, 2009). Although the reproductive cycles of males and females are different-with males apparently having a one-year cycle-, their overall numbers probably remain constant, thus would affect the actual high-risk area in terms of rate and absolute number of incidents but not location. As mentioned, currently, it is not known to what extent mature male white sharks visit the parturition area and contribute to the foundation of the low-risk areas or affect the density of the young-of-the-year white sharks and other juvenile white sharks through cannibalism. However, comparing the HRZs and LRZs and considering the known migration patterns and site fidelities of white sharks would indicate that the pregnant females have the greatest influence on the risk intensity of these zones.

\subsection{Value of Cluster Analysis for Analyzing Shark Attacks}

Spatial statistics is applied in many fields (e.g., Amin, Bohnert, Holmes, Rajasekaran, \& Assanasen, 2010; Coulston \& Riitters, 2003; Sudakin, Horowitz, \& Giffin, 2002). Following the Florida study (Amin et al., 2012), this project is the second attempt at applying cluster analysis to identify high- and low-risk shark-attack zones. Probably the most important value in using this form of cluster analysis is the ability to quantify the relative risk of being bitten by a shark, a tool that was not previously available by considering only the reported number of bites per area. This application of this type of evaluation was conducted to show how a shark species and its behavioral patterns could be used to explain such risk areas. However, other factors beyond species could be used to reveal previously hidden relationships between incident rates and beach population, thereby offering a base for further research.

\section{Acknowledgments}

We thank Peter Kennedy for his help in evaluating data. 


\section{References}

Abrams, A., Kleinman, K., \& Kulldorff, M. (2010). Gumbel based p-value approximation for spatial scan statistics. International Journal of Health Geographics, 9, 61. http://dx.doi.org/10.1186/1476-072X-9-61

Amin, R., Bohnert, A., Holmes, L., Rajasekaran, A., \& Assanasen, C. (2010). Epidemiologic mapping of Florida childhood cancer clusters. Pediatric Blood and Cancer, 54(4), 511-518. http://dx.doi.org/10.1002/pbc.22403

Amin, R., Ritter, E., \& Kennedy, P. (2012). A geospatial analysis of shark attack rates for the east coast of Florida: 1994-2009. Marine and Freshwater Behaviour and Physiology, 45(3), 185-198. http://dx.doi.org/10.1080/10236244.2012.715742

Collier, R. S. (1992). Recurring attacks by white sharks on divers at two Pacific sites off Mexico and California. Environmental Biology of Fishes, 33, 319-325.

Coulston, J. W., \& Riitters, K. H. (2003). Geographic analysis of forest health indicators using spatial scan statistics. Environmental Management, 31, 764-773. http://dx.doi.org/10.1007/s00267-002-0023-9

Dewar, H., Domeier, M., \& Nasby-Lucas, N. (2004). Insights into young of the year white shark, Carcharodon carcharias, behavior in the Southern California Bight. Environmental Biology of Fishes, 70, 133-143.

Domeier, M., \& Nasby-Lucas, N. (2008). Migration patterns of white shark Carcharodon carcharias tagged at Guadalupe Island, Mexico, and identification of an eastern Pacific shared offshore foraging area. Marine Ecology Progress Series, 370, 221-237. http://dx.doi.org/10.3354/meps07628

Jorgensen, S. J., Reeb, C. A., Chapple, T. K., Anderson, S., Perle, C., Van Sommeran S. R., Block, B. A. (2009). Philopatry and migration of Pacific white sharks. Proceedings of the Royal Society, 277(1682), 679-688.

Kelly, J. T., \& Klimley, A. P. (2003). The occurrence of the white shark Carcharodon carcharias, at the Point Reyes headlands, California. California Fish and Game, 89(4), 187-196.

McCosker, J. E., \& Lea, R. N. (2006). White shark attacks upons humans in California and Oregon, 1993-2003. Proceedings of the California Academy of Sciences, 57(17), 479-501.

Mollet, H. F., Cliff, G., Pratt, H. L., \& Stevens, J. (2000). Reproductive biology of the female shortfin mako, Isurus oxyrinchus Rafinesque, 1810, with comments on the embryonic development of lamnoids. US National Marine Fisheries Service Fishery Bulletin, 98, 299-318.

Nasby-Lucas, N., Dewar, H., Lam, C. H., Goldman, K. J. \& Domeier, M. L. (2009). White shark offshore habitat: A behavioral and environmental characterization of the Eastern Pacific shared offshore foraging area. PLoS ONE, 4(12), e8163. 


\section{Macrothink}

http://dx.doi.org/10.1371/journal.pone.0008163

Ritter, E. K., \& Amin, R. W. (2012). Effect of human body position on the swimming behavior of bull sharks, Carcharhinus leucas. Society and Animals, 20, 225-235. http://dx.doi.org/10.1163/15685306-12341235

Ritter, E. K., \& Levine, M. (2004). Use of forensic analysis to better understand shark attack behaviour. Journal of Forensic Odonto-Stomatology, 22(2), 40-46.

Ritter, E. K., \& Levine, M. (2005). Bite motivation of sharks reflected by the wound structure on humans. American Journal of Forensic Medicine and Pathology, 26(2), 136-40.

Shark Research Institute. (2012). Global shark attack file incident log. Retrieved from http://www.sharkattackfile.net/incidentlog.htm

Sudakin, D. L, Horowitz, Z., \& Giffin, S. (2002). Regional variation in the incidence of symptomatic pesticide exposures: Applications of geographic information systems. Clinical Toxicology, 40, 767-773. 